\title{
The co-occurrence of predicate clefting and WH-Questions in Trinidad dialectal English
}

\author{
Franz K. Cozier
}

Published online: 26 October 2006

(C) Springer Science+Business Media B.V. 2006

\section{Erratum to: Nat Lang Linguist Theory}

DOI: 10.1007/s11049-006-2962-y

Two footnotes published in this article unfortunately contained some errors. Please find the correct footnotes below:

${ }^{11}$ This example is slightly better than the others. This seems true of complements vs. adjuncts in general.

${ }^{20}$ This is similar to the meaning that one gets from verb doubling constructions in Biblical Hebrew (Genesis 2:17):

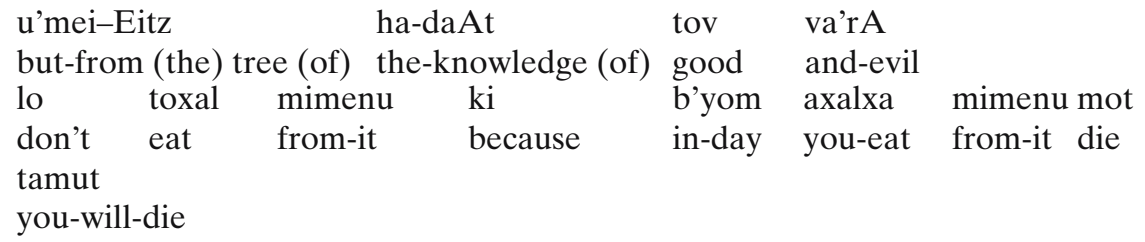

'But from the tree of the knowledge of good and evil, don't eat from it because in the day you eat from it (it is true, not false) that you will DIE.'

The online version of the original article can be found at http://dx.doi.org/10.1007/s11049-006-2962-y

F. K. Cozier $(\bowtie)$

Department of Linguistics and Philosophy

Massachusetts Institute of Technology

77 Mass Avenue, Bldg. 32-D808

Cambridge, MA 02139-4307, USA

e-mail: cozier@mit.edu 